\title{
Strong convergence theorem for strict pseudo-contractions in Hilbert spaces
}

\author{
Giuseppe Marino ${ }^{1,2^{*}}$, Bruno Scardamaglia' and Erdal Karapinar ${ }^{3}$
}

"Correspondence:
gmarino@unical.it
${ }^{1}$ Department of Mathematics and
Computer Sciences, University of
Calabria, Rende, Italy
${ }^{2}$ Department of Mathematics, King
Abdulaziz University, P.O. Box 80203 ,
Jeddah, Saudi Arabia
Full list of author information is
available at the end of the article

available at the end of the article

\section{照 Springer}

\begin{abstract}
In this paper, inspired by Hussain et al. (Fixed Point Theory Appl. 2015:17, 2015), we study a modified Mann method to approximate strongly fixed points of strict pseudo-contractive mappings. In (Hussain et al. in Fixed Point Theory Appl. 2015:17, 2015) it is shown that the same algorithm converges strongly to a fixed point of a nonexpansive mapping under suitable hypotheses on the coefficients. Here the assumptions on the coefficients are different, as well as the techniques of the proof.

MSC: 47J20; 47J25; 49J40; 65J15

Keywords: Mann's iterations; strict pseudo-contractions mappings; variational inequalities; Mainge's lemma
\end{abstract}

\section{Introduction}

Let $H$ be a real Hilbert space with the inner product $\langle\cdot, \cdot\rangle$, which induces the norm $\|\cdot\|$.

Let $C$ be a nonempty, closed, and convex subset of $H$. Let $T$ be a nonlinear mapping of $C$ into itself; we denote with $\operatorname{Fix}(T)$ the set of fixed points of $T$, that is, $\operatorname{Fix}(T)=\{z \in C$ : $T z=z\}$.

We recall that a mapping $T: C \rightarrow C$ is said to be $k$-strict pseudo-contractive (in the sense of Browder-Petryshyn) if there exists $k \in[0,1)$ such that

$$
\|T x-T y\|^{2} \leq\|x-y\|^{2}+k\|(I-T) x-(I-T) y\|^{2}, \quad \forall x, y \in C .
$$

Note that the class of strict pseudo-contractions includes the class of nonexpansive mappings, which are mappings $T$ on $C$ such that

$$
\|T x-T y\| \leq\|x-y\|, \quad \forall x, y \in C .
$$

The problem of finding fixed points of nonexpansive mappings via Mann's algorithm [2] has been widely investigated in the literature (see e.g. [3]).

Mann's algorithm generates, on initializing with an arbitrary $x_{1} \in C$, a sequence according to the recursive formula

$$
x_{1} \in C, \quad x_{n+1}=\alpha_{n} x_{n}+\left(1-\alpha_{n}\right) T x_{n}, \quad \forall n \geq 1,
$$

where $\left(\alpha_{n}\right)_{n \in \mathbb{N}} \subset(0,1)$.

(c) 2016 Marino et al. This article is distributed under the terms of the Creative Commons Attribution 4.0 International License (http://creativecommons.org/licenses/by/4.0/), which permits unrestricted use, distribution, and reproduction in any medium, provided you give appropriate credit to the original author(s) and the source, provide a link to the Creative Commons license, and indicate if changes were made. 
If $T: C \rightarrow C$ is a nonexpansive mapping with a fixed point in a closed and convex subset of a uniformly convex Banach space with a Frechét differentiable norm, and if the control sequence $\left(\alpha_{n}\right)_{n \in \mathbb{N}}$ is chosen so that $\sum_{n=1}^{\infty} \alpha_{n}\left(1-\alpha_{n}\right)=\infty$, then the sequence $\left(x_{n}\right)$ generated by Mann's algorithm converges weakly to a fixed point of $T$ [3]. However, this convergence is in general not strong (see the counterexample in [4]).

On the other hand, iterative algorithms for strict pseudo-contractions are still less developed than those for nonexpansive mappings, despite the pioneering work of Browder and Petryshyn [5] dating from 1967. However, strict pseudo-contractions have many applications, due to their ties with inverse strongly monotone operators. Indeed, if $A$ is a strongly monotone operator, then $T=I-A$ is a strict pseudo-contraction, and so we can redraft a problem of zeros for $A$ in a fixed point problem for $T$, and vice versa (see e.g. [6, 7]).

The Mann algorithm has weak convergence also in the broader setting of strict pseudocontractions mapping, containing the nonexpansive mappings.

Theorem 1.1 (Marino and Xu [8], 2007, Mann's method) Let $C$ be a closed and convex subset of a Hilbert space $H$. Let $T: C \rightarrow C$ be a $k$-strict pseudo-contraction for some $0 \leq$ $k<1$. Assume that $T$ admits a fixed point in $C$. Let $\left(x_{n}\right)$ be the sequence generated by $x_{0} \in C$ and the Mann algorithm

$$
x_{n+1}=\alpha_{n} x_{n}+\left(1-\alpha_{n}\right) T x_{n} .
$$

Assume that the control sequence $\left(\alpha_{n}\right)$ is chosen so that $k<\alpha_{n}<1$ for all $n$ and

$$
\sum_{n=0}^{+\infty}\left(\alpha_{n}-k\right)\left(1-\alpha_{n}\right)=+\infty
$$

Then $\left(x_{n}\right)$ converges weakly to a fixed point of $T$.

It is not possible, in general, to obtain strong convergence, in view of the celebrated counterexample of Genel and Lindenstrauss [4].

So, to obtain strong convergence, one can try to modify the Mann algorithm and strengthen the hypotheses on the mapping.

We recall here some obtained results.

Theorem 1.2 (Li et al. [9], 2013, modified Halpern's method) Let C be a closed and convex subset of a real Hilbert space $H, T: C \rightarrow C$ be a $k$-strict pseudo-contraction such that $\operatorname{Fix}(T) \neq \emptyset$. For an arbitrary initial value $x_{0} \in C$ and fixed anchor $u \in C$, define iteratively a sequence $\left(x_{n}\right)$ as follows:

$$
x_{n+1}=\alpha_{n} u+\beta_{n} x_{n}+\gamma_{n} T x_{n}
$$

where $\left(\alpha_{n}\right),\left(\beta_{n}\right),\left(\gamma_{n}\right)$ are three real sequences in $(0,1)$ satisfying $\alpha_{n}+\beta_{n}+\gamma_{n}=1$ and $0<k<$ $\frac{\beta_{n}}{\beta_{n}+\gamma_{n}}$. Suppose that $\left(\alpha_{n}\right)$ satisfies the conditions:

$$
\lim _{n \rightarrow \infty} \alpha_{n}=0, \quad \sum_{n=1}^{+\infty} \alpha_{n}=+\infty .
$$


Then $\left(x_{n}\right)$ converges strongly to $x^{*}=P_{\mathrm{Fix}(T)} u$, where $P_{\mathrm{Fix}(T)}$ is the metric projection from $H$ onto $\operatorname{Fix}(T)$.

Theorem 1.3 (Marino and Xu [8], 2007, CQ method) Let C be a closed convex subset of a Hilbert space $H$. Let $T: C \rightarrow C$ be a $k$-strict pseudo-contraction for some $0 \leq k<1$ and assume that $\operatorname{Fix}(T) \neq \emptyset$. Let $\left(x_{n}\right)$ be the sequence generated by the following $(C Q)$ algorithm:

$$
\left\{\begin{array}{l}
x_{0} \in C \\
y_{n}=\alpha_{n} x_{n}+\left(1-\alpha_{n}\right) T x_{n} \\
C_{n}=\left\{z \in C:\left\|y_{n}-z\right\|^{2} \leq\left\|x_{n}-z\right\|^{2}+\left(1-\alpha_{n}\right)\left(k-\alpha_{n}\right)\left\|x_{n}-T x_{n}\right\|^{2}\right\}, \\
Q_{n}=\left\{z \in C:\left\langle x_{n}-z, x_{0}-x_{n}\right\rangle \geq 0\right\} \\
x_{n+1}=P_{C_{n} \cap D_{n}} x_{0} .
\end{array}\right.
$$

Assume that the control sequence $\left(\alpha_{n}\right)$ is chosen so that $\alpha_{n}<1$ for all $n$. Then $\left(x_{n}\right)$ converges strongly to $P_{\mathrm{Fix}(T)} x_{0}$.

Theorem 1.4 (Shang [10], 2007, viscosity method) Let $C$ be a closed convex subset of a Hilbert space $H$ and let $T: C \rightarrow C$ be a k-strict pseudo-contraction with $\operatorname{Fix}(T) \neq \emptyset$. Let $f: C \rightarrow C$ be a contraction. The initial value $x_{0} \in C$ is chosen arbitrarily, and we have sequences $\left(\alpha_{n}\right)$ and $\left(\beta_{n}\right)$ satisfying the following conditions:

(1) $\lim _{n \rightarrow \infty} \alpha_{n}=0, \sum_{n=1}^{+\infty} \alpha_{n}=+\infty$;

(2) $0<a<\beta_{n}<\gamma$ for some $a \in(0, \gamma]$ and $\gamma=\min \{1,2 k\}$;

(3) $\sum_{n=1}^{+\infty}\left|\alpha_{n+1}-\alpha_{n}\right|<+\infty$ and $\sum_{n=1}^{+\infty}\left|\beta_{n+1}-\beta_{n}\right|<+\infty$.

Let $\left(x_{n}\right)$ be the composite process defined by

$$
\left\{\begin{array}{l}
y_{n}=\left(1-\beta_{n}\right) x_{n}+\beta_{n} T x_{n}, \\
x_{n+1}=\alpha_{n} f\left(x_{n}\right)+\left(1-\alpha_{n}\right) y_{n} .
\end{array}\right.
$$

Then $\left(x_{n}\right)$ converges strongly to a fixed point $p \in \operatorname{Fix}(T)$.

Theorem 1.5 (Osilike and Udomene [11], 2001, Ishikawa type method) Let H be a Hilbert space. Let $C$ be a nonempty, closed, and convex subset of $H, T: C \rightarrow C$ a demicompact $k$-strict pseudo-contraction with $\operatorname{Fix}(T) \neq \emptyset$. Let $\left(\alpha_{n}\right)$ and $\left(\beta_{n}\right)$ be real sequences in $[0,1]$ satisfying the following conditions:

(1) $0<a<\alpha_{n} \leq b<(1-k)\left(1-\beta_{n}\right), \forall n \geq 1$ and for some constants $a, b \in(0,1)$;

(2) $\sum_{n=1}^{+\infty} \beta_{n}<+\infty$.

Then the sequence $\left(x_{n}\right)$ generated from an arbitrary $x_{1} \in K$ by the Ishikawa iteration method

$$
\left\{\begin{array}{l}
y_{n}=\left(1-\beta_{n}\right) x_{n}+\beta_{n} T x_{n} \\
x_{n+1}=\left(1-\alpha_{n}\right) x_{n}+\alpha_{n} T x_{n}, \quad n \geq 1,
\end{array}\right.
$$

converges strongly to a fixed point of $T$.

The mentioned results are probably neither the most general, nor the more recent, but certainly they represent very well some of the different modifications of the original Mann approximation method, made to get strong convergence.

We would like to point out that the differences with the original method are remarkable. So it is quite surprising that recently, in [1] there was obtained a strong convergence 
method for nonexpansive mappings that is 'almost' the Mann method (the difference is given only by a smaller and smaller amount). In [1] was proved the convergence of this method only for nonexpansive mappings.

Theorem 1.6 (Hussain, Marino et al. [1], 2015) Let $H$ be a Hilbert space and $T: H \rightarrow H$ a nonexpansive mapping. Let $\left(\alpha_{n}\right),\left(\mu_{n}\right)$ be sequences in $(0,1]$ such that

- $\lim _{n \rightarrow \infty} \alpha_{n}=0$

- $\sum_{n=1}^{+\infty} \alpha_{n} \mu_{n}=+\infty$

- $\left|\mu_{n+1}-\mu_{n}\right|=o\left(\mu_{n}\right)$

- $\left|\alpha_{n+1}-\alpha_{n}\right|=o\left(\alpha_{n} \mu_{n}\right)$.

Then the sequence $\left(x_{n}\right)$ generated by

$$
x_{n+1}=\alpha_{n} x_{n}+\left(1-\alpha_{n}\right) T x_{n}-\alpha_{n} \mu_{n} x_{n}
$$

strongly converges to a point $x^{*} \in \operatorname{Fix}(T)$ with minimum norm

$$
\left\|x^{*}\right\|=\min _{x \in \operatorname{Fix}(T)}\|x\| .
$$

We would like to emphasize that:

(1) In general, the mapping $T$ cannot be defined on a closed convex subset $C$ of $H$, since $x_{n+1}$ is not a convex combination of two elements in $C$. However, since we can write

$$
x_{n+1}=\alpha_{n}\left(1-\mu_{n}\right) x_{n}+\left(1-\alpha_{n}\right) T x_{n},
$$

then $x_{n+1}$ is meaning full if $T: C \rightarrow C$ is a self-mapping defined on a cone $C$, that is, a particular convex set, closed with respect to linear combinations with positive coefficients.

(2) The proof of Theorem 1.6 is easy using the properties of nonexpansive mappings and cannot be adjusted to the strict pseudo-contractive mappings. The purpose of the present paper is to show that the result is true also for strict pseudo-contractions. The proof uses completely different techniques, as well as the assumptions on coefficients. For all we know, this is the algorithm most similar to the original iterative Mann's method (and the one most easy to implement), providing strong convergence.

(3) Our techniques can also be used to clarify the proofs of main results in [12] and [13].

\section{Preliminaries}

We need some tools in a real Hilbert space $H$, and some facts about $k$-strict pseudocontractive mappings which are listed in the following auxiliary lemmas.

The first result is very well known and easy to prove.

Lemma 2.1 Let $H$ be a Hilbert space, then:

(i) $\|t x+(1-t) y\|^{2}=t\|x\|^{2}+(1-t)\|y\|^{2}-t(1-t)\|x-y\|^{2}$, for all $x, y \in H$ and for all $t \in[0,1]$

(ii) $\|x+y\|^{2} \leq\|x\|^{2}+2\langle y, x+y\rangle$, for all $x, y \in H$.

A pertinent tool for us is the following well-known lemma of Xu. 
Lemma 2.2 [14] Let $\left(a_{n}\right)_{n \in \mathbb{N}}$ be a sequence of nonnegative real numbers satisfying the following relation:

$$
a_{n+1} \leq\left(1-\alpha_{n}\right) a_{n}+\alpha_{n} \sigma_{n}+\gamma_{n}, \quad n \geq 0,
$$

where:

- $\left(\alpha_{n}\right)_{n \in \mathbb{N}} \subset[0,1], \sum_{n=1}^{\infty} \alpha_{n}=\infty$;

- $\lim \sup _{n \rightarrow \infty} \sigma_{n} \leq 0$;

- $\gamma_{n} \geq 0, \sum_{n=1}^{\infty} \gamma_{n}<\infty$

Then we have

$$
\lim _{n \rightarrow \infty} a_{n}=0 .
$$

Lemma 2.3 Let $C$ a nonempty, closed, and convex subspace of $H, T$ a mapping from $C$ into itself such that $I-T$ is demiclosed at 0 , let $\left(y_{n}\right) \subset C$ be a bounded sequence.

$$
\text { If }\left\|y_{n}-T y_{n}\right\| \rightarrow 0 \text {, then }
$$

$$
\limsup _{n}\left\langle-\bar{p}, y_{n}-\bar{p}\right\rangle \leq 0,
$$

where $\bar{p}=P_{\mathrm{Fix}(T)}(0)$ is the unique point in $\operatorname{Fix}(T)$ that satisfies the variational inequality

$$
\langle-\bar{p}, x-\bar{p}\rangle \leq 0, \quad \forall x \in \operatorname{Fix}(T)
$$

Proof Let $\bar{p}$ satisfy (2.1). Let $\left(y_{n_{k}}\right)$ be a subsequence of $\left(y_{n}\right)$ for which

$$
\limsup _{n}\left\langle-\bar{p}, y_{n}-\bar{p}\right\rangle=\lim _{k}\left\langle-\bar{p}, y_{n_{k}}-\bar{p}\right\rangle
$$

Select a subsequence $\left(y_{n_{k_{j}}}\right)$ of $\left(y_{n_{k}}\right)$ such that $y_{n_{k_{j}}} \rightarrow v$ (this is possible by the boundedness of $\left.\left(y_{n}\right)\right)$. By the hypothesis $\left\|y_{n}-T y_{n}\right\| \rightarrow 0$, and by demiclosedness of $I-T$, we have $v \in$ Fix $(T)$, and

$$
\limsup _{n}\left\langle-\bar{p}, y_{n}-\bar{p}\right\rangle=\lim _{j}\left\langle-\bar{p}, y_{n_{k_{j}}}-\bar{p}\right\rangle=\langle-\bar{p}, v-\bar{p}\rangle .
$$

So the claim follows by (2.1).

Finally, a crucial tool for our results is the following lemma, proved by Maingé.

Lemma 2.4 [15] Let $\left(\gamma_{n}\right)_{n \in \mathbb{N}}$ be a sequence of real numbers such that there exists a subsequence $\left(\gamma_{n_{j}}\right)_{j \in \mathbb{N}}$ of $\left(\gamma_{n}\right)_{n \in \mathbb{N}}$ such that $\gamma_{n_{j}}<\gamma_{n_{j}+1}$, for all $j \in \mathbb{N}$. Then there exists a nondecreasing sequence $\left(m_{k}\right)_{k \in \mathbb{N}}$ of $\mathbb{N}$ such that $\lim _{k \rightarrow \infty} m_{k}=\infty$ and the following properties are satisfied by all (sufficiently large) numbers $k \in \mathbb{N}$ :

$$
\gamma_{m_{k}} \leq \gamma_{m_{k}+1} \text { and } \quad \gamma_{k} \leq \gamma_{m_{k}+1}
$$

In fact, $m_{k}$ is the largest number $n$ in the set $\{1, \ldots, k\}$ such that the condition $\gamma_{n}<\gamma_{n+1}$ holds. 
Before proving our convergence result for strict pseudo-contractions, we recall some properties of these mappings.

Lemma 2.5 [8] Assume $C$ is a closed convex subset of a Hilbert space $H$ and $T: C \rightarrow C$ be a self-mapping of $C$. If $T$ is a $k$-strict pseudo-contraction, then:

(1) $T$ satisfies the Lipschitz condition:

$$
\|T x-T y\| \leq \frac{1+k}{1-k}\|x-y\|
$$

(2) the mapping $I-T$ is demiclosed at 0 ; that is, if $\left(x_{n}\right)$ is a sequence in $C$ such that $x_{n} \rightarrow \hat{x}$ and $(I-T) x_{n} \rightarrow 0$, then $T \hat{x}=\hat{x}$

(3) the set $\operatorname{Fix}(T)=\{x \in C: T x=x\}$ is closed and convex, so that the projection $P_{\mathrm{Fix}(T)}$ is well defined.

Moreover, we have the following auxiliary result.

Lemma 2.6 Let be $T: C \rightarrow C$ a $k$-strict pseudo-contractive self-mapping of a closed and convex subset of a Hilbert space $H$, and suppose that $\operatorname{Fix}(T) \neq \emptyset$; then

$$
(1-k)\|T x-x\|^{2} \leq 2\langle x-p, x-T x\rangle, \quad \forall p \in \operatorname{Fix}(T), \forall x \in C .
$$

Proof Let $p \in \operatorname{Fix}(T)$. Putting $y=p$ in the definition of $T$, we get

$$
\|T x-p\|^{2} \leq\|x-p\|^{2}+k\|x-T x\|^{2}
$$

so

$$
\begin{aligned}
& \langle T x-p, T x-p\rangle \leq\langle x-p, x-T x\rangle+\langle x-p, T x-p\rangle+k\|x-T x\|^{2} \\
& \Rightarrow \quad\langle T x-p, T x-x\rangle \leq\langle x-p, x-T x\rangle+k\|x-T x\|^{2} \\
& \Rightarrow \quad\langle T x-x, T x-x\rangle+\langle x-p, T x-x\rangle \leq\langle x-p, x-T x\rangle+k\|x-T x\|^{2}
\end{aligned}
$$

from which we get (2.2).

\section{The main result}

Now we can prove our theorem. We use the notation $\omega_{l}\left(x_{n}\right)$ to denote the set of weak limit points of $\left(x_{n}\right)$.

Theorem 3.1 Let $H$ be a Hilbert space and let $C$ be a nonempty closed cone of $H$. Let $T: C \rightarrow C$ be a $k$-strict pseudo-contractive mapping such that $\operatorname{Fix}(T) \neq \emptyset$. Suppose that $\left(\alpha_{n}\right)_{n \in \mathbb{N}}$ and $\left(\mu_{n}\right)_{n \in \mathbb{N}}$ are real sequences, respectively, in $(k, 1)$ and in $(0,1)$ satisfying the conditions:

(1) $k<\liminf _{n \rightarrow \infty} \alpha_{n} \leq \limsup _{n \rightarrow \infty} \alpha_{n}<1$;

(2) $\lim _{n \rightarrow \infty} \mu_{n}=0$;

(3) $\sum_{n=1}^{\infty} \mu_{n}=\infty$. 
Let us define a sequence $\left(x_{n}\right)_{n \in \mathbb{N}}$ as follows:

$$
x_{1} \in C, \quad x_{n+1}=\alpha_{n}\left(1-\mu_{n}\right) x_{n}+\left(1-\alpha_{n}\right) T x_{n}, \quad n \in \mathbb{N} .
$$

Then $\left(x_{n}\right)_{n \in \mathbb{N}}$ converges strongly to $\bar{x} \in \operatorname{Fix}(T)$, that is, the unique solution of the variational inequality

$$
\langle-\bar{x}, y-\bar{x}\rangle \leq 0, \quad \forall y \in \operatorname{Fix}(T)
$$

Proof We begin by proving that $\left(x_{n}\right)_{n \in \mathbb{N}}$ is bounded.

First of all, observe that from the conditions $\mu_{n} \rightarrow 0$ and $k<\liminf \alpha_{n} \leq \lim \sup \alpha_{n}<1$, it follows that there exists an integer $n_{0} \in \mathbb{N}$ such that

$$
\mu_{n} \leq 1-\frac{k}{\alpha_{n}}, \quad \forall n \geq n_{0},
$$

i.e.

$$
k-\alpha_{n}\left(1-\mu_{n}\right) \leq 0
$$

Let be $p \in \operatorname{Fix}(T)$ and put $r=\max \left\{\left\|x_{n_{0}}-p\right\|,\|p\|\right\}$. We have

$$
\begin{aligned}
x_{n+1}-p & =\alpha_{n}\left[\left(1-\mu_{n}\right) x_{n}-p\right]+\left(1-\alpha_{n}\right)\left[T x_{n}-p\right] \\
& =\alpha_{n}\left[\left(1-\mu_{n}\right)\left(x_{n}-p\right)+\mu_{n}(-p)\right]+\left(1-\alpha_{n}\right)\left[T x_{n}-p\right] .
\end{aligned}
$$

Regarding Lemma 2.1(ii), we derive that

$$
\begin{aligned}
\left\|x_{n+1}-p\right\|^{2}= & \alpha_{n}\left\|\left(1-\mu_{n}\right)\left(x_{n}-p\right)+\mu_{n}(-p)\right\|^{2}+\left(1-\alpha_{n}\right)\left\|T x_{n}-p\right\|^{2} \\
& -\alpha_{n}\left(1-\alpha_{n}\right)\left\|\left(1-\mu_{n}\right) x_{n}-T x_{n}\right\|^{2} \\
\leq & \alpha_{n}\left[\left(1-\mu_{n}\right)\left\|x_{n}-p\right\|^{2}+\mu_{n}\|p\|^{2}-\mu_{n}\left(1-\mu_{n}\right)\left\|x_{n}\right\|^{2}\right] \\
& +\left(1-\alpha_{n}\right)\left[\left\|x_{n}-p\right\|^{2}+k\left\|x_{n}-T x_{n}\right\|^{2}\right] \\
& -\alpha_{n}\left(1-\alpha_{n}\right)\left\|\left(1-\mu_{n}\right)\left(x_{n}-T x_{n}\right)+\mu_{n}\left(-T x_{n}\right)\right\|^{2} \\
= & \alpha_{n}\left[\left(1-\mu_{n}\right)\left\|x_{n}-p\right\|^{2}+\mu_{n}\|p\|^{2}-\mu_{n}\left(1-\mu_{n}\right)\left\|x_{n}\right\|^{2}\right] \\
& +\left(1-\alpha_{n}\right)\left[\left\|x_{n}-p\right\|^{2}+k\left\|x_{n}-T x_{n}\right\|^{2}\right] \\
& -\alpha_{n}\left(1-\alpha_{n}\right)\left[\left(1-\mu_{n}\right)\left\|x_{n}-T x_{n}\right\|^{2}+\mu_{n}\left\|T x_{n}\right\|^{2}-\mu_{n}\left(1-\mu_{n}\right)\left\|x_{n}\right\|^{2}\right] \\
\leq & \alpha_{n}\left(1-\mu_{n}\right)\left\|x_{n}-p\right\|^{2}+\alpha_{n} \mu_{n}\|p\|^{2}+\left(1-\alpha_{n}\right)\left\|x_{n}-p\right\|^{2} \\
& +\left(1-\alpha_{n}\right) k\left\|x_{n}-T x_{n}\right\|^{2}-\alpha_{n}\left(1-\alpha_{n}\right)\left(1-\mu_{n}\right)\left\|x_{n}-T x_{n}\right\|^{2} \\
= & \left(1-\alpha_{n} \mu_{n}\right)\left\|x_{n}-p\right\|^{2}+\alpha_{n} \mu_{n}\|p\|^{2}+\left(1-\alpha_{n}\right)\left[k-\alpha_{n}\left(1-\mu_{n}\right)\right]\left\|x_{n}-T x_{n}\right\|^{2} \\
(\text { from }(3.2)) \leq & \left(1-\alpha_{n} \mu_{n}\right)\left\|x_{n}-p\right\|^{2}+\alpha_{n} \mu_{n}\|p\|^{2} \\
\leq & \max \left\{\left\|x_{n}-p\right\|^{2},\|p\|^{2}\right\} \leq \max \left\{\left\|x_{n_{0}}-p\right\|^{2},\|p\|^{2}\right\}=r^{2} .
\end{aligned}
$$

Thus, we conclude that the sequence $\left(x_{n}\right)$ is bounded. 
Now we shall prove that, for $p \in \operatorname{Fix}(T)$,

$$
\begin{gathered}
\left(1-\alpha_{n}\right)\left(\alpha_{n}-k\right)\left\|x_{n}-T x_{n}\right\|^{2} \leq \\
\left(\left\|x_{n}-p\right\|^{2}-\left\|x_{n+1}-p\right\|^{2}\right) \\
-2 \alpha_{n} \mu_{n}\left\langle x_{n}, x_{n+1}-p\right\rangle
\end{gathered}
$$

Regarding (3.1), we easily observe that

$$
\begin{aligned}
x_{n+1}-p & =\alpha_{n}\left(1-\mu_{n}\right) x_{n}+\left(1-\alpha_{n}\right) T x_{n}-p \\
& =\left[1-\left(1-\alpha_{n}\left(1-\mu_{n}\right)\right)\right] x_{n}+\left(1-\alpha_{n}\right) T x_{n}-p \\
& =\left(x_{n}-p\right)-\left(1-\alpha_{n}\right)\left(x_{n}-T x_{n}\right)-\alpha_{n} \mu_{n} x_{n},
\end{aligned}
$$

and so

$$
\begin{aligned}
\left\|x_{n+1}-p\right\|^{2} \leq & \left\|\left(x_{n}-p\right)-\left(1-\alpha_{n}\right)\left(x_{n}-T x_{n}\right)\right\|^{2}-2 \alpha_{n} \mu_{n}\left\langle x_{n}, x_{n+1}-p\right\rangle \\
= & \left\|x_{n}-p\right\|^{2}-2\left(1-\alpha_{n}\right)\left\langle x_{n}-T x_{n}, x_{n}-p\right\rangle \\
& +\left(1-\alpha_{n}\right)^{2}\left\|x_{n}-T x_{n}\right\|^{2}-2 \alpha_{n} \mu_{n}\left\langle x_{n}, x_{n+1}-p\right\rangle \\
(\text { from }(2.2)) \leq & \left\|x_{n}-p\right\|^{2}+\left(1-\alpha_{n}\right)\left(k-\alpha_{n}\right)\left\|x_{n}-T x_{n}\right\|^{2}-2 \alpha_{n} \mu_{n}\left\langle x_{n}, x_{n+1}-p\right\rangle,
\end{aligned}
$$

so (3.3) is proved. Moreover, since $\alpha_{n} \in(k, 1)$,

$$
\left\|x_{n+1}-p\right\|^{2} \leq\left\|x_{n}-p\right\|^{2}-2 \alpha_{n} \mu_{n}\left\langle x_{n}, x_{n+1}-p\right\rangle
$$

Now we prove the strong convergence of $\left(x_{n}\right)$ concerning two cases:

Case 1 . Suppose that $\left\|x_{n}-p\right\|$ is monotone nonincreasing. Then $\left\|x_{n}-p\right\|$ converges and hence

$$
\lim _{n \rightarrow \infty}\left\|x_{n+1}-p\right\|^{2}-\left\|x_{n}-p\right\|^{2}=0
$$

From this and from the assumptions $\lim _{n} \mu_{n}=0$, and $k<\liminf _{n} \alpha_{n} \leq \limsup _{n} \alpha_{n}<1$, by (3.3) we get

$$
\lim _{n \rightarrow \infty}\left\|x_{n}-T x_{n}\right\|=0
$$

from this and boundedness of $\left(x_{n}\right)$, thanks to demiclosedness of $I-T$ we deduce $\omega_{l}\left(x_{n}\right) \subseteq$ $\operatorname{Fix}(T)$.

Now we put

$$
z_{n}=\alpha_{n} x_{n}+\left(1-\alpha_{n}\right) T x_{n}=\left(1-\left(1-\alpha_{n}\right)\right) x_{n}+\left(1-\alpha_{n}\right) T x_{n},
$$

from which we have

$$
z_{n}-x_{n}=\left(1-\alpha_{n}\right)\left(T x_{n}-x_{n}\right)
$$


Hence, we find that

$$
\begin{aligned}
x_{n+1} & =z_{n}-\alpha_{n} \mu_{n} x_{n} \\
& =\left(1-\alpha_{n} \mu_{n}\right) z_{n}+\alpha_{n} \mu_{n}\left(z_{n}-x_{n}\right) \\
(\text { from }(3.4)) & =\left(1-\alpha_{n} \mu_{n}\right) z_{n}+\alpha_{n} \mu_{n}\left(1-\alpha_{n}\right)\left(T x_{n}-x_{n}\right) .
\end{aligned}
$$

Let $\bar{x}=P_{\operatorname{Fix}(T)}(0) \in \operatorname{Fix}(T)$ the unique solution of the variational inequality

$$
\langle-\bar{x}, y-\bar{x}\rangle \leq 0, \quad \forall y \in \operatorname{Fix}(T)
$$

From the definition of $z_{n}$,

$$
\begin{aligned}
\left\|z_{n}-\bar{x}\right\|^{2} & =\left\|x_{n}-\bar{x}-\left(1-\alpha_{n}\right)\left(x_{n}-T x_{n}\right)\right\|^{2} \\
& =\left\|x_{n}-\bar{x}\right\|^{2}-2\left(1-\alpha_{n}\right)\left\langle x_{n}-T x_{n}, x_{n}-\bar{x}\right\rangle+\left(1-\alpha_{n}\right)\left\|x_{n}-T x_{n}\right\|^{2} \\
(\operatorname{from}(2.2)) & \leq\left\|x_{n}-\bar{x}\right\|^{2}-\left(1-\alpha_{n}\right)\left[(1-k)-\left(1-\alpha_{n}\right)\right]\left\|x_{n}-T x_{n}\right\|^{2} \\
& \leq\left\|x_{n}-\bar{x}\right\|^{2} .
\end{aligned}
$$

So,

$$
\begin{aligned}
\left\|x_{n+1}-\bar{x}\right\|^{2}= & (\text { from }(3.5))=\left\|\left(1-\alpha_{n} \mu_{n}\right) z_{n}+\alpha_{n} \mu_{n}\left(1-\alpha_{n}\right)\left(T x_{n}-x_{n}\right)-\bar{x}\right\|^{2} \\
= & \left\|\left(1-\alpha_{n} \mu_{n}\right)\left(z_{n}-\bar{x}\right)+\alpha_{n} \mu_{n}\left[\left(1-\alpha_{n}\right)\left(T x_{n}-x_{n}\right)-\bar{x}\right]\right\|^{2} \\
(\text { from Lemma 2.1) } \leq & \left(1-\alpha_{n} \mu_{n}\right)^{2}\left\|z_{n}-\bar{x}\right\|^{2}+2 \alpha_{n} \mu_{n}\left(\left(1-\alpha_{n}\right)\left(T x_{n}-x_{n}\right), x_{n+1}-\bar{x}\right\rangle \\
& +2 \alpha_{n} \mu_{n}\left\langle-\bar{x}, x_{n+1}-\bar{x}\right\rangle \\
(\text { from (3.7)) } \leq & \left(1-\alpha_{n} \mu_{n}\right)\left\|x_{n}-\bar{x}\right\|^{2} \\
& +2 \alpha_{n} \mu_{n}\left(\left(1-\alpha_{n}\right)\left\langle T x_{n}-x_{n}, x_{n+1}-\bar{x}\right\rangle+\left\langle-\bar{x}, x_{n+1}-\bar{x}\right\rangle\right) .
\end{aligned}
$$

Now, since $\left(x_{n}\right)$ is bounded and $\omega_{l}\left(x_{n}\right) \subseteq \operatorname{Fix}(T)$, there exists an appropriate subsequence $x_{n_{k}} \rightarrow p_{0} \in \operatorname{Fix}(T)$ such that

$$
\limsup _{n}\left\langle-\bar{x}, x_{n+1}-\bar{x}\right\rangle=\lim _{k}\left\langle-\bar{x}, x_{n_{k}}-\bar{x}\right\rangle=\left\langle-\bar{x}, p_{0}-\bar{x}\right\rangle \leq 0
$$

From this, it follows that all the hypotheses of Lemma 2.2 are satisfied and finally by (3.8) we can conclude

$$
\lim _{n \rightarrow \infty}\left\|x_{n}-\bar{x}\right\|=0
$$

Let now $\bar{x} \in \operatorname{Fix}(T)$ be defined by the variational inequality (3.6).

Case 2. If $\left\|x_{n}-\bar{x}\right\|$ does not be monotone nonincreasing, there exists a subsequence $\left(x_{n_{k}}\right)$ such that $\left\|x_{n_{k}}-\bar{x}\right\|<\left\|x_{n_{k}+1}-\bar{x}\right\|, \forall k \in \mathbb{N}$. So by Lemma $2.4, \exists \tau(n) \uparrow+\infty$ such that

(1) $\left\|x_{\tau(n)}-\bar{x}\right\|<\left\|x_{\tau(n)+1}-\bar{x}\right\|$;

(2) $\left\|x_{n}-\bar{x}\right\|<\left\|x_{\tau(n)+1}-\bar{x}\right\|$. 
Now, we have

$$
\begin{aligned}
0 & \leq \liminf _{n}\left(\left\|x_{\tau(n)+1}-\bar{x}\right\|-\left\|x_{\tau(n)}-\bar{x}\right\|\right) \\
& \leq \limsup _{n}\left(\left\|x_{\tau(n)+1}-\bar{x}\right\|-\left\|x_{\tau(n)}-\bar{x}\right\|\right) \\
& \leq \limsup _{n}\left(\left\|x_{n+1}-\bar{x}\right\|-\left\|x_{n}-\bar{x}\right\|\right) \\
& \leq \limsup _{n}\left(\left\|x_{n}-\bar{x}\right\|+\sqrt{\mu_{n}} M-\left\|x_{n}-\bar{x}\right\|\right)=0 .
\end{aligned}
$$

Thus, we derive that

$$
\left\|x_{\tau(n)+1}-\bar{x}\right\|^{2}-\left\|x_{\tau(n)}-\bar{x}\right\|^{2} \longrightarrow 0,
$$

from which

$$
\left\|x_{\tau(n)}-T x_{\tau(n)}\right\| \longrightarrow 0 .
$$

Now, from (3.8), we get

$$
\begin{aligned}
\left\|x_{\tau(n)+1}-\bar{x}\right\|^{2} \leq & \left(1-\alpha_{\tau(n)} \mu_{\tau(n)}\right)\left\|x_{\tau(n)}-\bar{x}\right\|^{2} \\
& +2 \alpha_{\tau(n)} \mu_{\tau(n)}\left(1-\alpha_{\tau(n)}\right)\left\langle T x_{\tau(n)}-x_{\tau(n)}, x_{\tau(n)+1}-\bar{x}\right\rangle \\
& +2 \alpha_{\tau(n)} \mu_{\tau(n)}\left\langle-\bar{x}, x_{\tau(n)+1}-\bar{x}\right\rangle \\
= & \left\|x_{\tau(n)}-\bar{x}\right\|^{2}+2 \alpha_{\tau(n)} \mu_{\tau(n)}\left(1-\alpha_{\tau(n)}\right)\left\langle T x_{\tau(n)}-x_{\tau(n)}, x_{\tau(n)+1}-\bar{x}\right\rangle \\
& +2 \alpha_{\tau(n)} \mu_{\tau(n)}\left\langle-\bar{x}, x_{\tau(n)+1}-\bar{x}\right\rangle \\
& -2 \alpha_{\tau(n)} \mu_{\tau(n)}\left(\frac{\left\|x_{\tau(n)}-\bar{x}\right\|^{2}}{2}\right) .
\end{aligned}
$$

Putting in (3.11)

$$
\begin{aligned}
A_{\tau(n)}= & \left(1-\alpha_{\tau(n)}\right)\left\langle T x_{\tau(n)}-x_{\tau(n)}, x_{\tau(n)+1}-\bar{x}\right\rangle \\
& +\left\langle-\bar{x}, x_{\tau(n)+1}-\bar{x}\right\rangle-\frac{\left\|x_{\tau(n)}-\bar{x}\right\|^{2}}{2},
\end{aligned}
$$

we have

$$
\left\|x_{\tau(n)+1}-\bar{x}\right\|^{2} \leq\left\|x_{\tau(n)}-\bar{x}\right\|^{2}+2 \alpha_{\tau(n)} \mu_{\tau(n)} A_{\tau(n)} .
$$

Notice that we cannot use Lemma 2.2 as in Case 1 (or in $[12,13]$ ) since we could not guarantee that $\sum_{n=1}^{+\infty} \mu_{\tau(n)}=+\infty$. So, we proceed as follows. Assume by contradiction that $\left\|x_{\tau(n)}-\bar{x}\right\|$ does not converge to 0 . Then there exist $\left(n_{j}\right)$ and an $\epsilon>0$ such that

$$
\left\|x_{\tau\left(n_{j}\right)}-\bar{x}\right\| \geq 2 \epsilon .
$$

By (3.9) and (3.10) we know that there exist $n_{0}, n_{1} \in \mathbb{N}$ such that

$$
\left(1-\alpha_{\tau(n)}\right)\left\langle T x_{\tau(n)}-x_{\tau(n)}, x_{\tau(n)+1}-\bar{x}\right\rangle<\frac{\epsilon}{3}, \quad \forall n \geq n_{0}
$$


and

$$
\left\langle-\bar{x}, x_{\tau(n)+1}-\bar{x}\right\rangle<\frac{\epsilon}{3}, \quad \forall n \geq n_{1} .
$$

Hence, if we take $n_{j_{0}} \geq \max \left\{n_{0}, n_{1}\right\}$ one obtains by the definition of $A_{\tau(n)}$,

$$
A_{\tau(n)}<\frac{\epsilon}{3}+\frac{\epsilon}{3}-\epsilon=-\frac{\epsilon}{3}<0, \quad \forall n \geq n_{j_{0}} .
$$

So, by (3.12) we have $\left\|x_{\tau(n)+1}-\bar{x}\right\|^{2} \leq\left\|x_{\tau(n)}-\bar{x}\right\|^{2}$, which contradicts $\left\|x_{\tau(n)}-\bar{x}\right\|<\| x_{\tau(n)+1}-$ $\bar{x} \|, \forall n$. This implies that

$$
\left\|x_{\tau(n)}-\bar{x}\right\| \longrightarrow 0
$$

and so, using $\left\|x_{n}-\bar{x}\right\|<\left\|x_{\tau(n)+1}-\bar{x}\right\|$, we finally obtain

$$
\left\|x_{n}-\bar{x}\right\| \longrightarrow 0
$$

Example 3.2 The mapping $T: \mathbb{R} \rightarrow \mathbb{R}$ defined by $T x=-2 x$ is $\frac{1}{3}$-strict pseudo-contractive. Taking $\alpha_{n}=\frac{1}{2}, \mu_{n}=\frac{1}{n}$, our algorithm becomes

$$
x_{n+1}=-\frac{1}{2} \frac{n+1}{n} x_{n}
$$

which goes to $0=\operatorname{Fix}(T)$ swinging around it.

\section{Open questions}

(1) Does the result hold in Banach spaces?

(2) Does the result hold for families of strict pseudo-contractive mappings?

(3) Does the result hold for Lipschitzian pseudo-contractive mappings?

\section{Competing interests}

The authors declare that they have no competing interests.

Authors' contributions

All authors contributed equally and significantly in writing the article. All authors read and approved the final manuscript.

\section{Author details}

'Department of Mathematics and Computer Sciences, University of Calabria, Rende, Italy. ${ }^{2}$ Department of Mathematics, King Abdulaziz University, P.O. Box 80203, Jeddah, Saudi Arabia. ${ }^{3}$ Department of Mathematics, Atilim University, Ankara, Turkey.

Received: 12 April 2016 Accepted: 19 April 2016 Published online: 06 May 2016

\section{References}

1. Hussain, N, Marino, G, Muglia, L, Alamri, BAS: On some Mann's type iterative algorithms. Fixed Point Theory Appl. 2015, 17 (2015)

2. Mann, WR: Mean value methods in iteration. Proc. Am. Math. Soc. 4, 506-510 (1953)

3. Reich, S: Weak convergence theorems for nonexpansive mappings in Banach spaces. J. Math. Anal. Appl. 67, 274-276 (1979)

4. Genel, A, Lindenstrauss, J: An example concerning fixed points. Isr. J. Math. 22, 81-86 (1975)

5. Browder, FE, Petrishyn, WV: Construction of fixed points of nonlinear mappings in Hilbert spaces. J. Math. Anal. Appl. 20, 197-228 (1967)

6. Chen, R, Yao, Y: Strong convergence theorems for strict pseudo-contractions in Hilbert spaces. J. Appl. Math. Comput. $32,69-82(2010)$

7. Shahazad, N, Zegeye, $\mathrm{H}$ : Approximating of common point of fixed points of a pseudo-contractive mapping and zeros of sum of monotone mappings. Fixed Point Theory Appl. 2014, 85 (2014) 
8. Marino, G, Xu, HK: Weak and strong convergence theorems for strict pseudo-contractions in Hilbert spaces. J. Math. Anal. Appl. 329, 336-346 (2007)

9. Li, L, Li, S, Zhang, L, He, X: Strong convergence of modified Halpern's iterations for a $k$-strictly pseudo-contractive mapping. J. Inequal. Appl. 2013, 98 (2013)

10. Shang, M, Ye, G: Strong convergence theorems for strictly pseudo-contractive mappings by viscosity approximation methods. Mod. Appl. Sci. 1, 19-23 (2007)

11. Osilike, MO, Udomene, A: Demiclosedness principle and convergence theorems for strictly pseudo-contractive mappings of Browder-Petryshyn type. J. Math. Anal. Appl. 256, 431-445 (2001)

12. Cianciaruso, F, Marino, G, Rugiano, A, Scardamaglia, B: On strong convergence of Halpern's method using averaged type mappings. J. Appl. Math. 2014, Article ID 473243 (2014)

13. Cianciaruso, F, Marino, G, Rugiano, A, Scardamaglia, B: On strong convergence of viscosity type method using averaged type mappings. J. Nonlinear Convex Anal. 16(8), 1619-1640 (2015)

14. Xu, HK: Iterative algorithms for nonlinear operators. J. Lond. Math. Soc. 2, 240-256 (2002)

15. Maingé, PE: Strong convergence of projected subgradient methods for nonsmooth and nonstrictly convex minimization. Set-Valued Anal. 16, 899-912 (2008)

Submit your manuscript to a SpringerOpen ${ }^{\circ}$ journal and benefit from:

- Convenient online submission

Rigorous peer review

- Immediate publication on acceptance

Open access: articles freely available online

- High visibility within the field

- Retaining the copyright to your article 